\title{
A new reaction route for the synthesis of 2-methyl-5-ethyl-pyridine
}

\section{Emanuele Moioli ${ }^{1,2}$, Leo Schmid ${ }^{2}$, Peter Wasserscheid ${ }^{1}$, Hannsjörg Freund ${ }^{1}$}

\author{
${ }^{1}$ Lehrstuhl für Chemische Reaktionstechnik, Friedrich-Alexander-Universität Erlangen-Nürnberg, Egerlandstrasse 3, \\ DE-91058 Erlangen, Germany \\ ${ }^{2}$ Specialty Ingredients Research \& Technology, Lonza Ltd., Lonzastrasse, CH-3930 Visp, Switzerland \\ Accepted version of the paper published in React. Chem. Eng., 2017, 2, 754, \\ https://doi.org/10.1039/c7re00100b
}

\begin{abstract}
In this work, a novel synthesis route to produce 2-methyl-5-ethyl-pyridine (MEP) from the cyclic acetaldehyde ammonia trimer (AAT) is explored. The reaction was studied in a semi-batch reactor in the presence of different promoters to adjust the $\mathrm{pH}$ of the reaction solution. Among various ammonium salts tested as promoters, ammonium acetate was identified as most suitable promoter for the reaction. By a Design of Experiments (DoE) approach temperature and concentration of reactants and promoter were identified as the most important/decisive parameters for influencing the course of the reaction. Additional mechanistic investigations were carried out to assess the effect of these parameters in detail and to clarify the by-product formation via oligomer formation.
\end{abstract}

\section{Introduction}

2-Methyl-5-ethyl-pyridine (MEP) is a largely produced pyridine base, currently used as intermediate for the production of nicotinic acid and nicotinamide, commercially named vitamin B3 or PP, respectively. MEP is also applied in the production of 2-methyl-5-vinylpyridine, an intermediate for the production of resins [14]. To date, the industrial production of MEP takes place via the so-called Chichibabin reaction, the condensation of aldehydes in the presence of ammonia [5]. Early studies [6-7] demonstrated the possibility to produce MEP by liquid phase condensation of acetaldehyde in the presence of ammonia using ammonium acetate as catalyst. On the other hand, it is not possible to produce MEP in high yield in gas phase via the Chichibabin reaction, since the main products of this reaction are 2- and 4-picoline (2- and 4methyl-pyridine) [8-10]. Nowadays, the industrial production of MEP takes place by reaction of paraldehyde and aqueous ammonia in the presence of a catalyst. This reaction is carried out at $200-300{ }^{\circ} \mathrm{C}$ and 12-13 MPa [5]. The yield to MEP of this reaction is about $70 \%$, with the simultaneous production of small amounts of other pyridine bases (mainly 2- and 4-picoline). The use of paraldehyde allows for a good reaction management, avoiding the spontaneous self-oligomerisation that is typical for acetaldehyde $[1,11]$. The reaction mechanism of MEP formation has been extensively studied, however, it is still under debate. All the proposed schemes involve as first step the production of aldimine $\left(\mathrm{CH}_{3} \mathrm{CHNH}\right)$ from acetaldehyde and ammonia [1,12]. This molecule tends to dimerise and trimerise by means of consecutive aldol reactions. At a certain chain length, the molecule undergoes a cyclisation to form the skeleton of the pyridine base. The mechanism of this cyclisation step is not well described in literature. It is, however, the key step to understand the selectivity of the reaction to MEP.

In this paper, an alternative reaction route to MEP using acetaldehyde ammonia trimer (AAT) instead of paraldehyde and ammonia as feedstock is introduced. AAT is a cyclic molecule readily formed when acetaldehyde and ammonia are mixed at room temperature [13-15]. The molecule can be isolated as a white solid and is soluble in water or methanol [14]. AAT has various uses in organic synthesis [16-18] and can be technically employed as scavenger for sulfhydryl compounds [19]. In a previous study [20] we reported on the $\mathrm{pH}$ influence on formation of AAT and identified the optimal conditions for this reaction. To the best of our knowledge, the direct use of AAT in the Chichibabin reaction has never been reported in 
literature as of today. In the following we describe the development of this new process route in three steps: a) the fundamental demonstration of the feasibility of the reaction and analysis of promoter effects on MEP yield, b) the determination of most influential parameters on MEP selectivity using a Design of Experiments (DoE) approach, and c) the detailed analysis of the mechanistic effect of these most influential parameters.

We also present a detailed comparison of the traditional MEP synthesis from paraldehyde (Figure 1a) and from the new route from AAT proposed in this work (Figure 1b). For this purpose, for the initial experiments with AAT the same promoters and operative conditions as applied for the standard reaction from paraldehyde were chosen $[5,20]$. The motivation to study this alternative reaction route and new process scheme for producing MEP stems from the observation that AAT is more reactive than paraldehyde but still easy to handle as solid or in solution in solvents such as, e.g., methanol or acetonitrile [16]. Another striking advantage is that the synthesis of MEP from AAT requires no additional ammonia or ammonia source since AAT already contains the nitrogen necessary for the product formation. This offers potential to simplify the reactor set-up and the process scheme significantly. In the here proposed production scheme of MEP, ammonia is directly fed in the first reactor dedicated to AAT production. This allows the main reactor for MEP production to operate at lower temperature and pressure. This simplifies the overall process, avoiding the need to feed pure ammonia at high temperature and pressure.
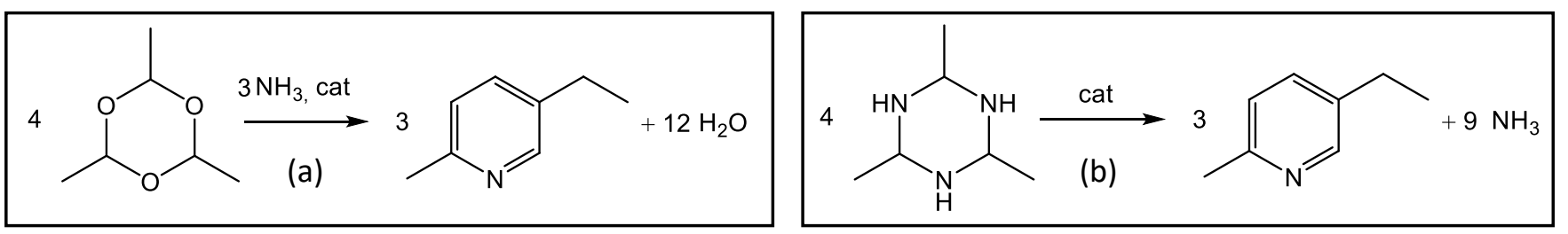

Figure 1 Schematic representation of the two reactions studied (a) para to MEP, (b) AAT to MEP.

\section{Experimental}

\section{Chemicals}

All applied chemicals, acetaldehyde ammonia trimer, ammonium salts (ammonium sulphate, ammonium nitrate, ammonium chloride, ammonium phosphate, ammonium fluoride and ammonium acetate), ammonium hydroxide ( $25 \%$ wt.), paraldehyde, methanol and acetic acid were purchased from Sigma Aldrich in $99 \%$ purity ( $96 \%$ for AAT). They were used as received.

\section{Preparation of MEP}

The reaction of AAT and paraldehyde to produce MEP was carried out in a $300 \mathrm{~mL}$ Hastelloy autoclave. 100 $\mathrm{mL}$ of aqueous solution of promoter (ammonium salt or acid) was charged into the reactor and heated up to the reaction temperature $\left(150-230^{\circ} \mathrm{C}\right)$ under stirring at $1000 \mathrm{rpm}$. When the solution of promoter reached the desired temperature, $100 \mathrm{~mL}$ of solution of AAT or paraldehyde in methanol was fed by an HPLC pump with a flow rate ranging from 5 to $20 \mathrm{~mL} / \mathrm{min}$. The pressure of the sealed reactor was not adjusted so that the reaction took place at the vapour pressure of the mixture. After addition of AAT or paraldehyde, the reaction was continued for two hours under heating and stirring. The reaction mixture was then cooled down to room temperature, the residual gas was released and the resulting solution was recovered for analysis. Throughout this study, the influencing parameters of the reaction were investigated via the same procedure as above, but varying the concentration of AAT or paraldehyde, concentration and type of the promoter and relative concentration of the two components.

\section{Analytics}


Product analysis was carried out using an Agilent A6850 gas chromatograph system equipped with FID (Flame lonisation Detector) and a HP-FFAP capillary column ( $25 \mathrm{~m} \times 0.2 \mathrm{~mm} \times 0.33 \mu \mathrm{m}$ ) using 3-picoline as internal standard. This was possible since 3-picoline was not observed to be produced by the reaction. The main product of the reaction is MEP, followed by 2- and 4-picoline. Other peaks that were identified by means of GC-MS were assigned to other pyridine bases (e.g. other methyl-ethyl-pyridines and heavier pyridine bases). The oligomer by-products were analysed by an Agilent liquid chromatography/hybrid quadrupole time-of-flight/mass spectrometer (LC/HQ-TOF/MS).

\section{Results and discussion}

\section{Influence of heating and substrate addition}

Figure 2 shows the results of the reaction carried out in two different reactor systems, batch and semibatch, and with three different reactants, acetaldehyde, paraldehyde or AAT. The first two sets of experiments were performed without addition of promoter. Note that it was not possible to produce MEP in the presence of promoter in a batch reactor as undesired oligomer formation consumed all feedstock already during the heating phase of the reactor. Without any ammonium salt promoter, the reaction in batch mode resulted in a low yield to MEP of approximately $15 \%$ independent on the use of acetaldehyde, paraldehyde or AAT as substrate. Also without the promoter significant oligomer formation was observed during the reactor heating phase, consuming most of the aldehyde precursor.

To avoid the detrimental influence of a prolonged heating phase, we next performed the reaction in a semibatch reactor. The solution containing the acetaldehyde, paraldehyde or ATT reactant was added over time by means of an HPLC pump to an equivalent volume of water under reaction temperature in the autoclave (typical pressure in the reactor was 20-30 bar). That way, improved, but still low yields of MEP were obtained, not exceeding $30 \%$ for all three reactants. Consequently, the amount of reactant lost during the heating phase can be quantified to about $15 \%$. An important parameter for the reaction to MEP is the $\mathrm{pH}$ of the aqueous reaction mixture. Due to the unbuffered presence of ammonia, $\mathrm{pH}$ was always high in all previous reactions. Following a literature report describing the production of pyridine bases from aldehydes and paraldehyde [21], we performed our next set of experiments under semi-batch conditions, but with addition of ammonium acetate as a buffer system to adjust the $\mathrm{pH}$. This indeed led to a strong increase of the MEP yield for all three substrates, up to $55 \%$ of MEP were obtained in the reaction mixture. This clearly confirms the feasibility of the reaction route from AAT to MEP. 


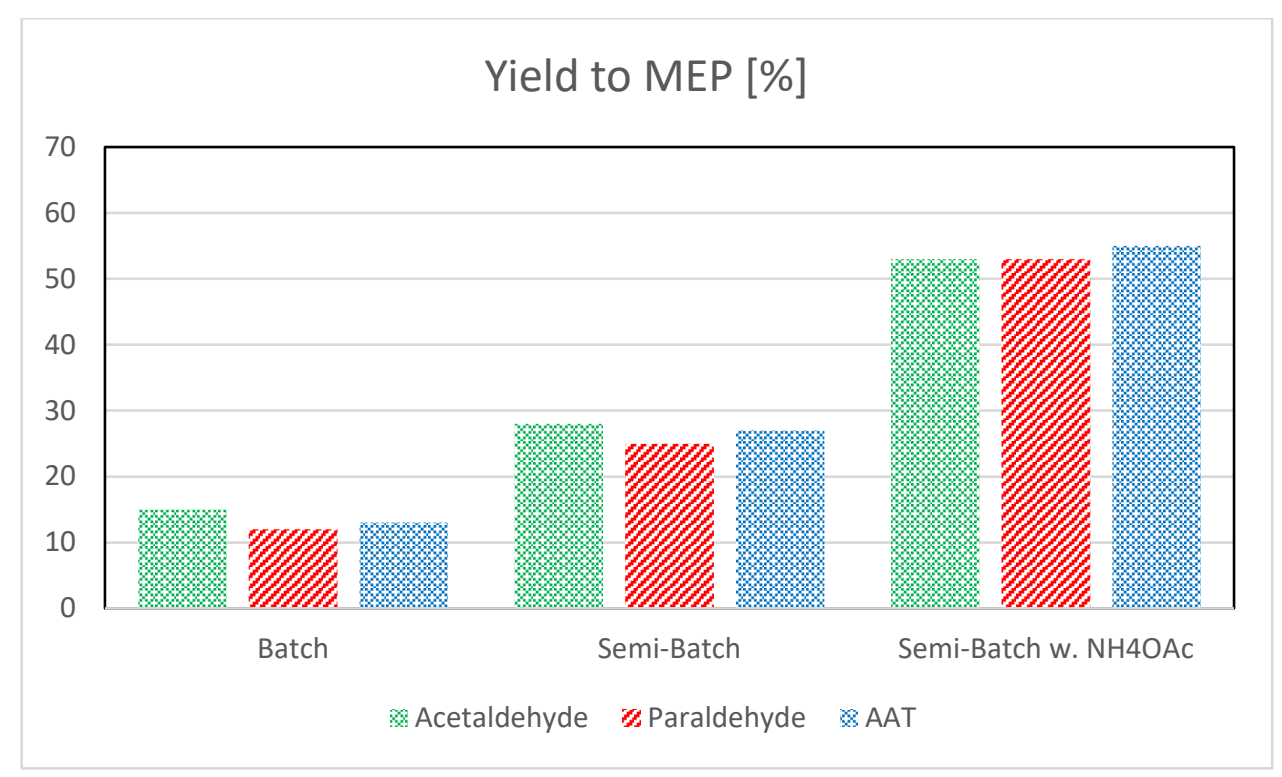

Figure 2 Effect of reactor type and presence of promoter on the reaction to MEP from acetaldehyde, paraldehyde and AAT. Reaction conditions: $T=200{ }^{\circ} \mathrm{C}$, concentration of reactant $10 \% \mathrm{wt}$., ratio acetaldehyde eq. $/$ promoter $=1 / 3 \mathrm{~mol} / \mathrm{mol}$, feeding rate $=10 \mathrm{~mL} / \mathrm{min}$

\section{Promoter screening}

To further optimize the MEP yield, solutions of several ammonium salts were tested as promoters. These solutions were prepared no ammonia was added during reaction. The results of the experiments are presented in Table 1. MEP is produced with over $50 \%$ yield in the presence of all ammonium salts selected. Interestingly, there is an increasing yield in MEP with increasing basicity of the ammonium salt counter-ion. The highest yield is obtained with ammonium acetate. The promoter is required to maintain the $\mathrm{pH}$ around 5-7 to favour the reaction to MEP over the undesired formation of oligomer.

In contrast to paraldehyde, AAT already contains nitrogen in its molecular structure so that additional ammonia (or the ammonium ion) is in theory not required to form MEP. For this reason, a further experimental run was carried out using acetic acid instead of ammonium acetate as promoter. The result of this run (Table 1, last column) is in line with the previous results leading to the important conclusion that the nitrogen atom found in the product origins from AAT and not from the ammonium promoter. Thus, any additive able to adjust the right $\mathrm{pH}$ in the aqueous solution under reaction conditions is probably suitable for promoting the formation of MEP.

Table 1 Results of the promoter screening. Reaction conditions: $T=200{ }^{\circ} \mathrm{C}$, concentration of reactant $10 \%$ wt.

\begin{tabular}{|l|c|c|c|c|c|c|c|}
\hline Catalyst & $\mathrm{NH}_{4} \mathrm{HSO}_{4}$ & $\mathrm{NH}_{4} \mathrm{Cl}$ & $\mathrm{NH}_{4} \mathrm{NO}_{3}$ & $\mathrm{NH}_{4} \mathrm{H}_{2} \mathrm{PO}_{4}$ & $\mathrm{NH}_{4} \mathrm{~F}$ & $\mathrm{NH}_{4} \mathrm{OAc}$ & $\mathrm{AcOH}$ \\
\hline Yield MEP [\%] & 50.3 & 53.6 & 55.8 & 56.4 & 56.8 & 58.9 & 57.5 \\
\hline
\end{tabular}

To further investigate the effect of $\mathrm{pH}$ on the reaction, some additional experiments with added ammonia and varying ratios of ammonia and ammonium salt were carried out. To exclude particular anion effects, the same set of experiments was performed with two different salts, ammonium acetate and ammonium fluoride. Keeping the overall molar amount of nitrogen in the promoter solution constant (and thus the ratio of AAT-based nitrogen to promoter-based nitrogen in the solution), the ratio of ammonium salts to ammonia $\left(\left[\mathrm{NH}_{4}\right] \mathrm{X}: \mathrm{NH}_{3}\right)$ was varied, from only ammonia $\left(0 \%\left[\mathrm{NH}_{4}\right] \mathrm{X}\right)$ to only ammonium salt $\left(100 \%\left[\mathrm{NH}_{4}\right] \mathrm{X}\right)$. The results of these experiments are shown in Figure 3. As already noted during the first tests, the yield in the absence of a promoter (high $\mathrm{pH}$ ) is low. The increase in ammonium salt content causes an increase of MEP yield until a maximum, which in turn is different for the two different ammonium salts. The different 
$\left[\mathrm{NH}_{4}\right] \mathrm{X}: \mathrm{NH}_{3}$ ratio for the maximum yield can be explained with the different $\mathrm{pH}$ values originating from the addition of the two different salts. Since addition of ammonium fluoride results in a stronger acidic solution than the addition of ammonium acetate, the solution of optimal $\mathrm{pH}$ is to be prepared with lower quantity of fluoride salt compared to ammonium acetate. From the results it is obvious that both, too low and too high $\mathrm{pH}$ is detrimental for the MEP yield as in both cases undesired oligomerisation competes successfully with the desired MEP formation. Obviously, the maximum MEP yield is higher with addition of the acetate salt promoter compared to the fluoride salt addition. Furthermore, the results reveal that the optimal $\mathrm{pH}$ range for maximising the MEP yield is between 8 and 9 .

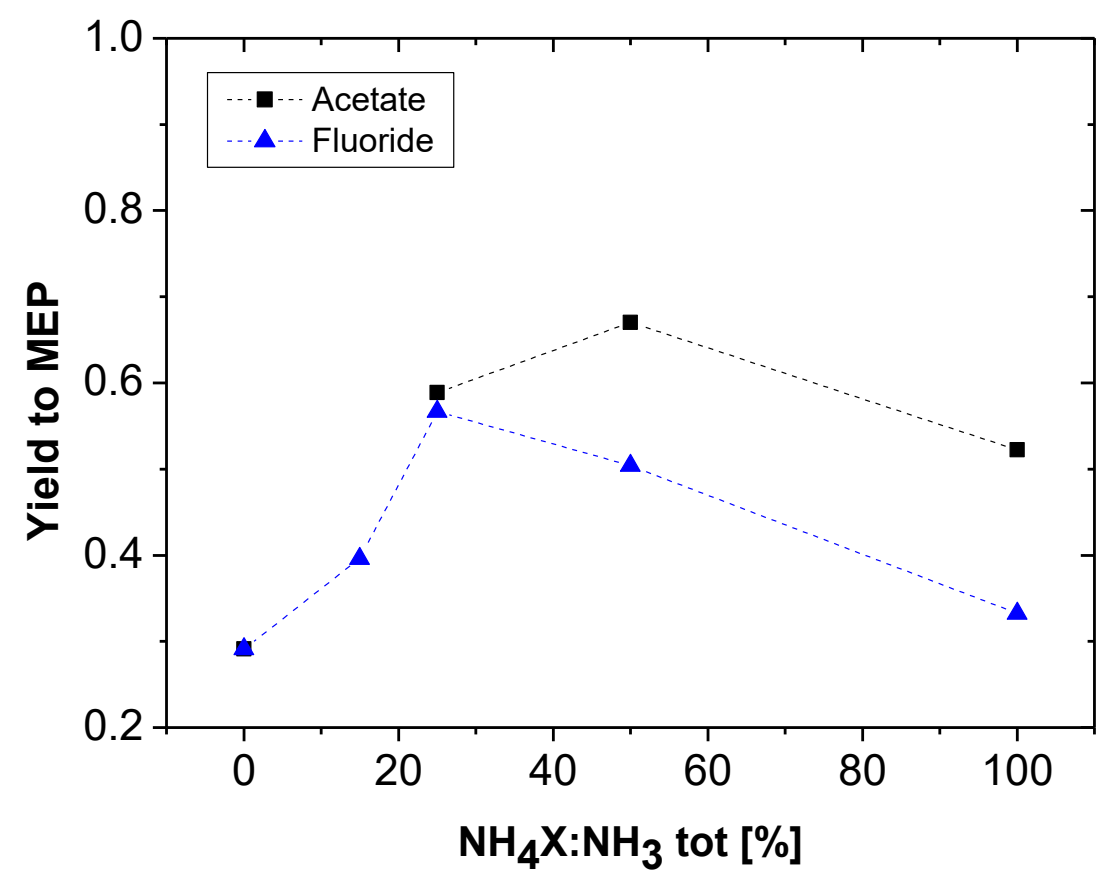

Figure 3. Effect of ammonia addition to ammonium salt promoters in MEP formation from AAT (0\%= only ammonia, 100\%= only ammonium salt). Reaction conditions: $T=200{ }^{\circ} \mathrm{C}$, concentration of reactant $10 \% \mathrm{wt}$. in water, ratio AAT $/ \mathrm{promoter}=1 / 1 \mathrm{~mol} / \mathrm{mol}$, feeding rate $=10 \mathrm{~mL} / \mathrm{min}$.

\section{Determination of the most influential reaction parameters by a Design of Experiments approach}

The following experiments were all carried out using ammonium acetate/acetic acid to promote the reaction and to adjust the right $\mathrm{pH}$ range. All experiments were performed in a semi-batch reactor. To determine the most influential parameters on MEP yield, a Design of Experiments (DoE) study was carried out. For this purpose, the initial run of the DoE was performed without promoter to solely investigate at first the influence of temperature as well as AAT and ammonia concentration. The extreme values of the reaction parameters were chosen in agreement with literature data referring to the process from paraldehyde [5]. These values are reported in Table 2. 
Table 2 Parameters investigated in the first DoE run.

\begin{tabular}{|l|l|l|l|}
\hline Factor name & Letter & Low value & High value \\
\hline Temperature $\left[{ }^{\circ} \mathrm{C}\right]$ & A & 160 & 200 \\
\hline Ammonia $[$ wt. $\%$ ] & B & 0 & 7.5 \\
\hline AAT $[$ wt. $\%]$ & C & 2 & 10 \\
\hline
\end{tabular}

The results are analysed by means of statistical methods to pinpoint the effects of the three factors on the MEP yield. The most efficient way to explain the variability of yield depending on the three factors is through a Pareto chart, which is shown in Figure 4. Amongst the three parameters temperature is the most relevant. An increase of temperature from the low set point to the high set point causes an average increase of yield from 15 to $20 \%$. This is a highly significant result as the centre point of the experimental run is about $15 \%$ yield (as reported in the previous sections). Following temperature, the second most important parameter is AAT concentration. An increase of AAT concentration from 2 to $10 \%$ causes a decrease in yield from 18 to $14 \%$. The negative influence of aldehyde concentration on yield is a wellknown effect in pyridine bases synthesis [22]. In contrast, the effect of ammonia concentration is small. Only a slight increase of yield is obtained when adding ammonia to the reaction solution. This minor influence of ammonia is most probably due to the presence of nitrogen in excess in the molecule of AAT with respect to the stoichiometry of the reaction. The increase of nitrogen has only a limited impact on the extent of undesired side reactions. For this reason, ammonia is not considered as a very important influencing parameter in the reaction and the successive experiments were carried out without addition of ammonia to the solution.

\section{Pareto DoE Run 1}

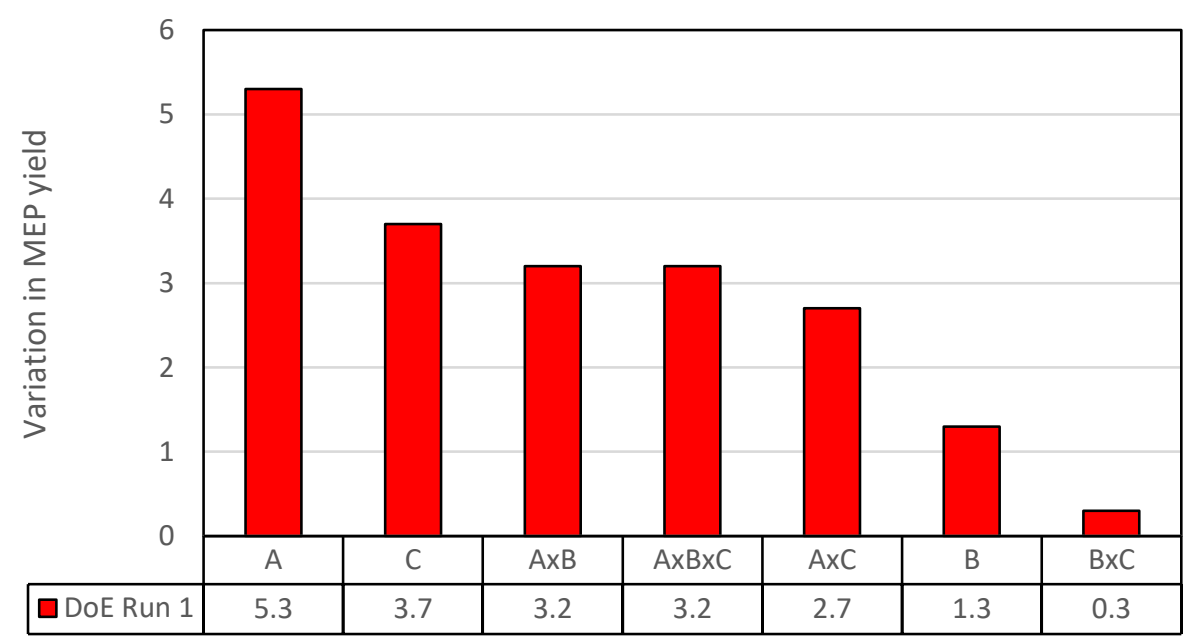

Figure 4 Pareto chart of the first DoE run. The effects plotted are the variation of yield due to the various factors. For the meaning of the letters, see Table 2.

A second run of DoE was conducted to determine the parametric influence of temperature and AAT concentration in the presence of ammonium acetate. The boundaries of this set of experiments are reported in Table 3. The upper and lower limits for temperature and AAT addition are the same as in the previous case. The addition of the ammonium acetate promoter ranges from 0 to $5 \mathrm{wt} \%$. 
Table 3 Parameters investigated in the second DoE run.

\begin{tabular}{|l|l|l|l|}
\hline Factor name & Letter & Low value & High value \\
\hline Temperature $\left[{ }^{\circ} \mathrm{C}\right]$ & A & 160 & 200 \\
\hline $\mathrm{NH}_{4} \mathrm{Ac}[$ wt. $\%$ ] & B & 0 & 5 \\
\hline AAT $[$ wt. $\%]$ & C & 2 & 10 \\
\hline
\end{tabular}

The results of the experimental runs are displayed in Figure 5. The influence of the promoter is the most important factor. The addition of $5 \%$ wt. promoter causes an average increase in yield from 15 to $45 \%$. This confirms that the promoter is necessary to reach a good yield to MEP. The effect of different amounts of promoter will be discussed below. The decrease of AAT concentration between the two boundary conditions causes an increase in yield from 23 to $37 \%$. This impact is much higher than in the previous case without promoter addition. The influence of temperature is now the weakest of the three factors studied. The combined influences are very limited.

\section{Pareto DoE run 2}

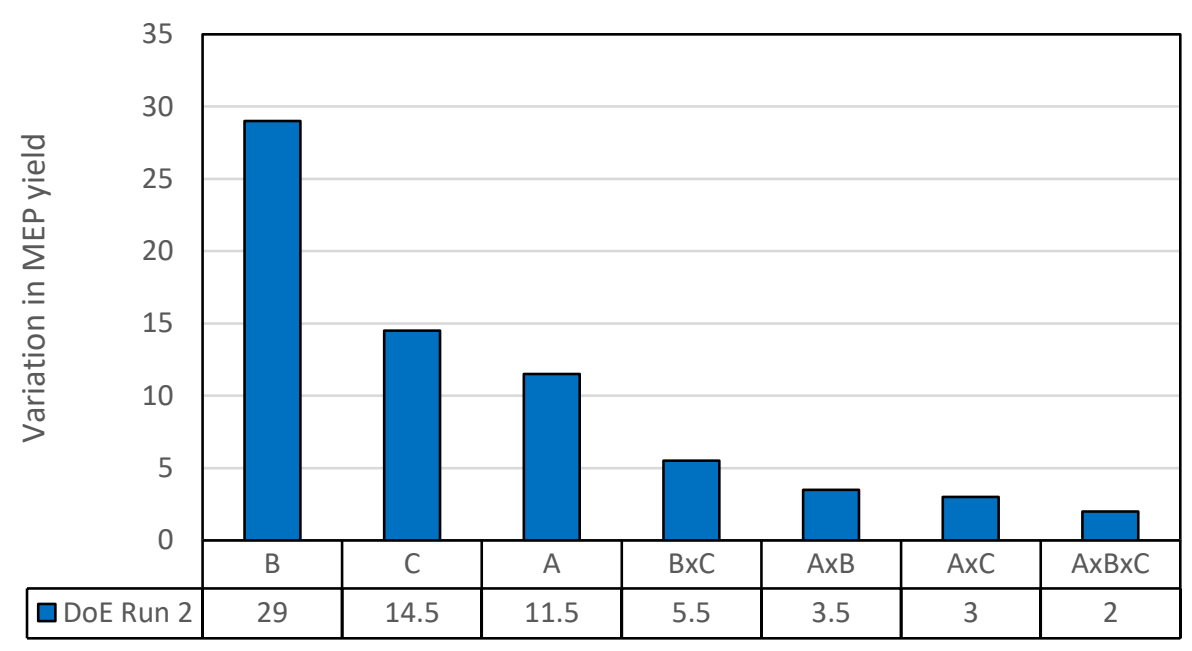

Figure 5 Pareto chart of the second DoE run. The effects plotted are the variation of yield due to the various factors. For the meaning of the letters, see Table 3. 
In a next set of experiments we studied the feed flow rate of AAT. For this purpose, experiments with feeding rate ranging from 1 to $20 \mathrm{~mL} / \mathrm{min}$ were carried out. The results are shown in Figure 6 . In this range, the yield is almost constant, so the feed flow rate is set for the following experiments to $10 \mathrm{~mL} / \mathrm{min}$.

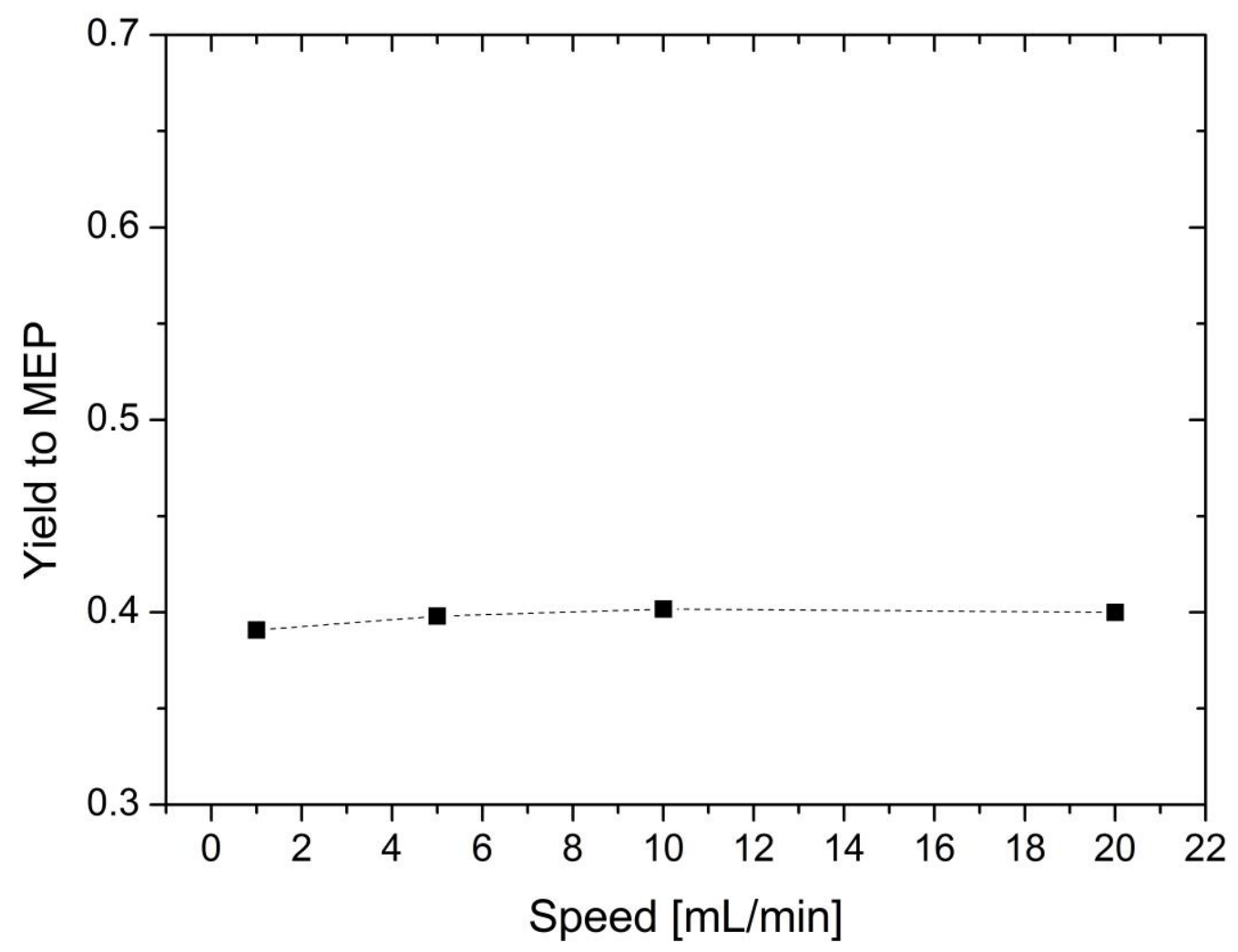

Figure 6 Effect of feeding rate on the yield of MEP. Reaction conditions: $T=200{ }^{\circ} \mathrm{C}$, concentration of reactant $5 \%$ wt., ratio $A A T /$ promoter $=1.0 \mathrm{~mol} / \mathrm{mol}$

\section{Mechanistic study of the reaction}

For the following mechanistic study of the reaction, all experiments were carried out both with paraldehyde and AAT. This allows studying the two reactions in direct comparison to find out whether MEP production from AAT is a suitable alternative to the current reaction route from paraldehyde.

The first parameter we evaluated in detail is temperature. The experimental results are displayed in Figure 7. The yield to MEP increases linearly in the range between $150-200{ }^{\circ} \mathrm{C}$ from 0.3 to 0.6 . This is due to the increasing rate of MEP formation with temperature compared to oligomerisation. Note that for temperatures above $200{ }^{\circ} \mathrm{C}$ the MEP yield is decreasing again due to other thermally induced sidereactions. The temperature dependency of the reaction from AAT and from para is comparable. Additionally, the type and quantity of side product formation is independent of the substrate. The high similarity of both reactions is probably due to the formation of a common intermediate that is produced from either of the two different starting materials. 


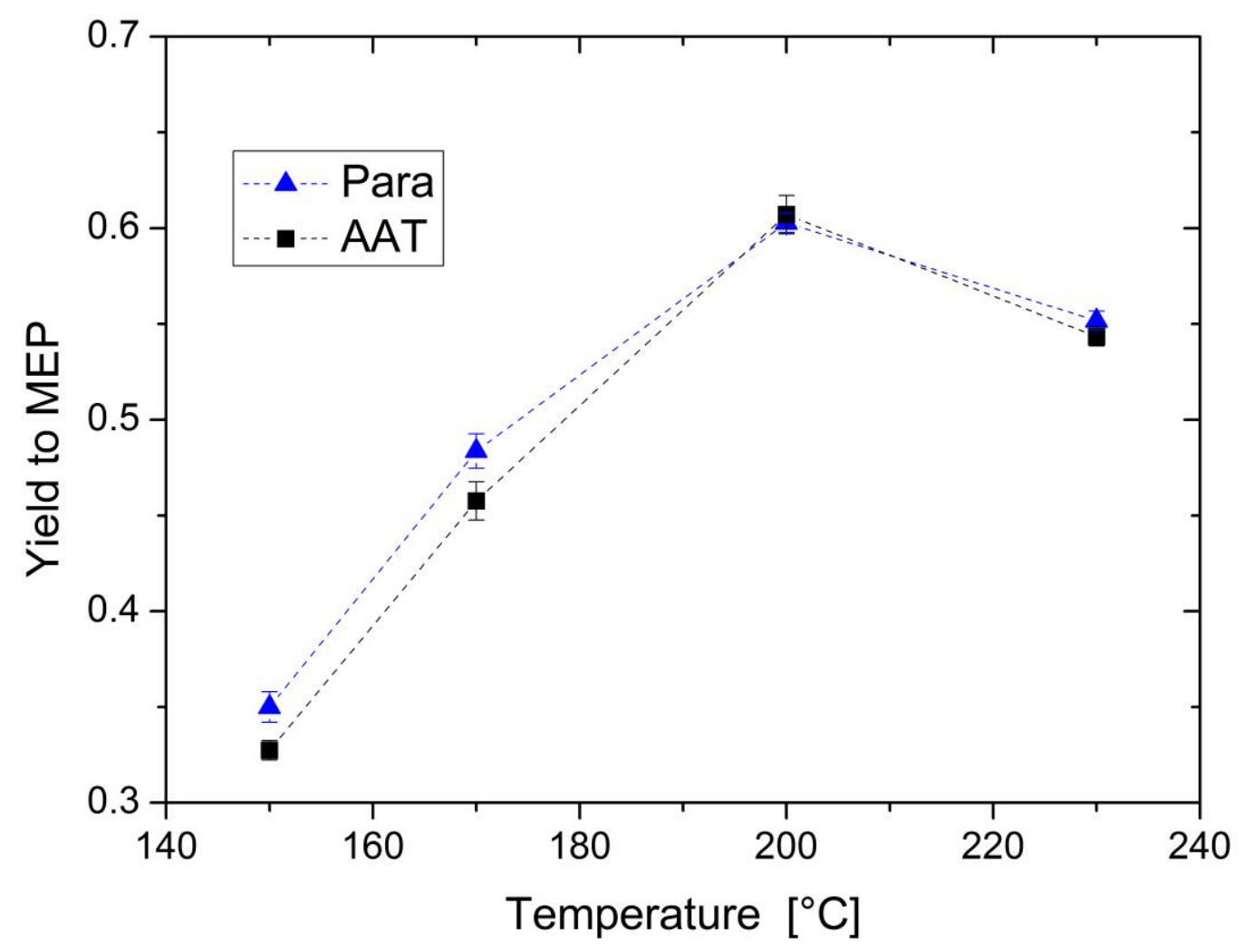

Figure 7 Effect of temperature on the yield of MEP. Reaction conditions: concentration of reactant $5 \%$ wt., ratio AAT/promoter $=1.0$ $\mathrm{mol} / \mathrm{mol}$, feed flow rate $=10 \mathrm{~mL} / \mathrm{min}$

The second parameter investigated during this mechanistic study is the concentration of the substrate (AAT or paraldehyde). The initial concentration of the reactant was varied from a low value ( $2 \% \mathrm{wt}$.$) to the$ solubility limit of AAT in methanol (ca. $20 \%$ wt.). The results are shown in Figure 8 . The increase in concentration has a strong negative influence on yield. Obviously, too high concentration of substrate pushes the balance between MEP formation and oligomerisation in favour of the latter. The GC-MS analyses of the product solutions showed the presence of many different side products, all of them with a molecular weight higher than MEP. Again, the two different substrates behave very similarly under all conditions under investigation. 


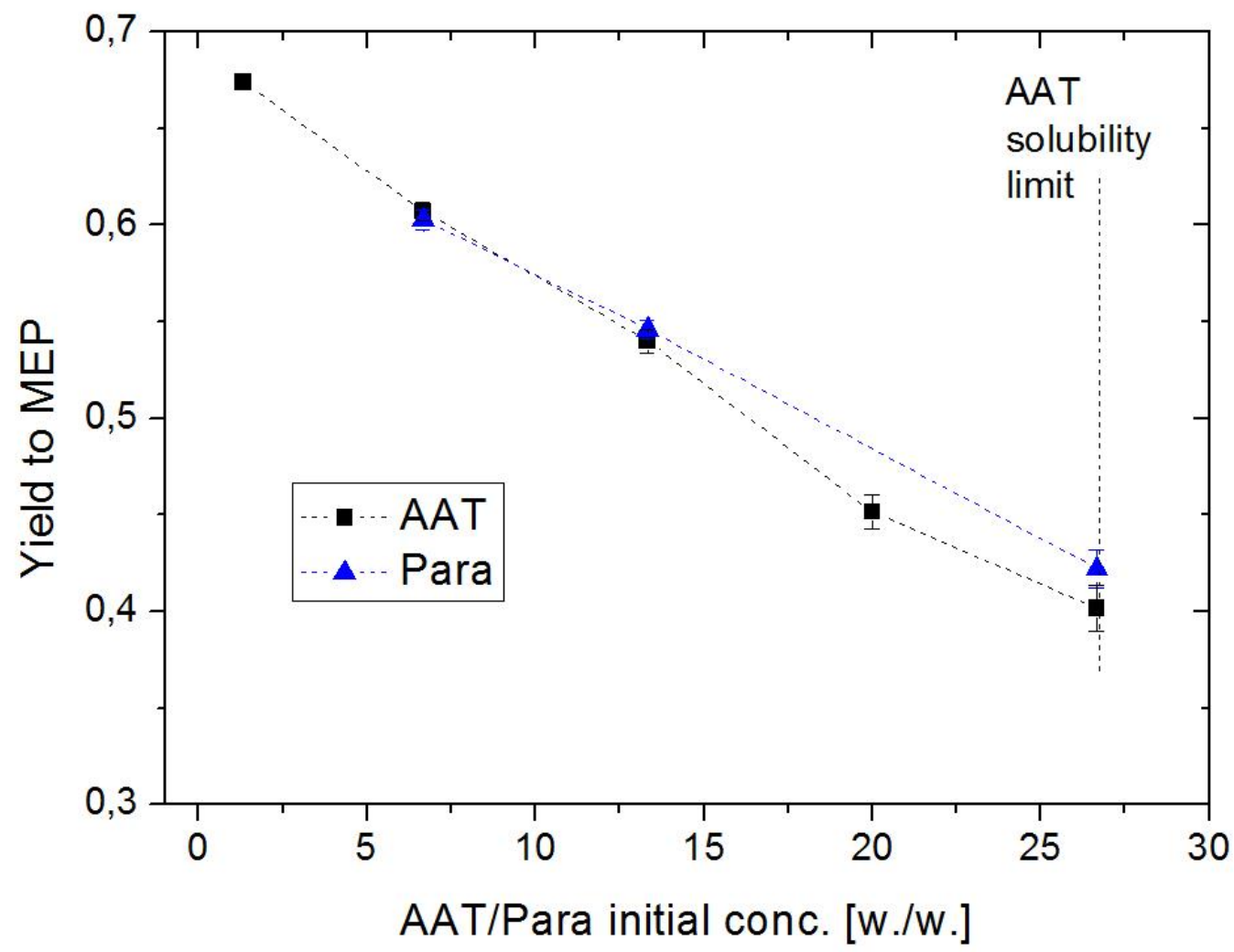

Figure 8 Effect of reactant concentration on yield of MEP. Reaction conditions: $T=200{ }^{\circ} \mathrm{C}$, ratio AAT $/$ promoter $=1.0 \mathrm{~mol} / \mathrm{mol}$, feed flow rate $=10 \mathrm{~mL} / \mathrm{min}$

In a next set of experiments we investigated in more detail the effect of different amounts of added promoter. Three different scenarios have been studied: The reaction of paraldehyde in the presence of ammonium acetate, the corresponding reaction of AAT in the presence of ammonium acetate and the reaction of AAT in the presence of acetic acid. The corresponding results are displayed in Figure 9.

To make the results comparable, the yield is plotted as a function of promoter to AAT or para molar ratio. The three series of experiments show different results. The reaction of AAT in the presence of ammonium acetate leads to a high yield in MEP for the entire range considered. At lower promoter concentration there is a slight increase in yield, from 55 to $60 \%$. This value remains constant when the concentration of promoter is further increased.

The results obtained with paraldehyde are quite different. The yield at lower promoter concentration is lower (ca. $45 \%$ ) and an increasing trend is observed until the yield reaches a maximum of ca. $60 \%$ at large excess of promoter. The yield at large excess of promoter is comparable for AAT and paraldehyde, confirming the previous observations. The different trend at lower concentration of promoter is due to the stoichiometric effect of ammonia in the two reactions. While AAT does not require ammonia to react to MEP, paraldehyde needs ammonia to form the precursor for the pyridine ring. Consequently, the reaction of AAT to MEP is carried on in excess of nitrogen independently from promoter concentration, thanks to the presence of nitrogen in the molecule. In contrast, the assumption of a limited influence of ammonia is not valid for the reaction using paraldehyde as the substrate. This reaction requires the presence of much more ammonia to yield the highest amount of MEP. 
To further assess the possibility to carry out the reaction of AAT to MEP in the absence of ammonia, the effect of acetic acid as promoter was also studied. Interestingly, the results of these experiments show a different trend compared to the reactions using ammonium acetate. Here, the MEP yield shows a maximum at a stoichiometric ratio slightly lower than that for the case of ammonium acetate. This behaviour is due to a pH effect. For ammonium acetate, the increase of concentration has only a limited effect on the $\mathrm{pH}$ of the solution while the change in concentration of acetic acid results in a stronger reduction of the $\mathrm{pH}$. Note that the use of acetic acid as promoter can yield the same results as for ammonium acetate, but this promoter leads to stronger shifts in $\mathrm{pH}$ resulting in a smaller window of optimal yields. The use of acetic acid as promoter allows carrying out the reaction with no additional ammonia source.

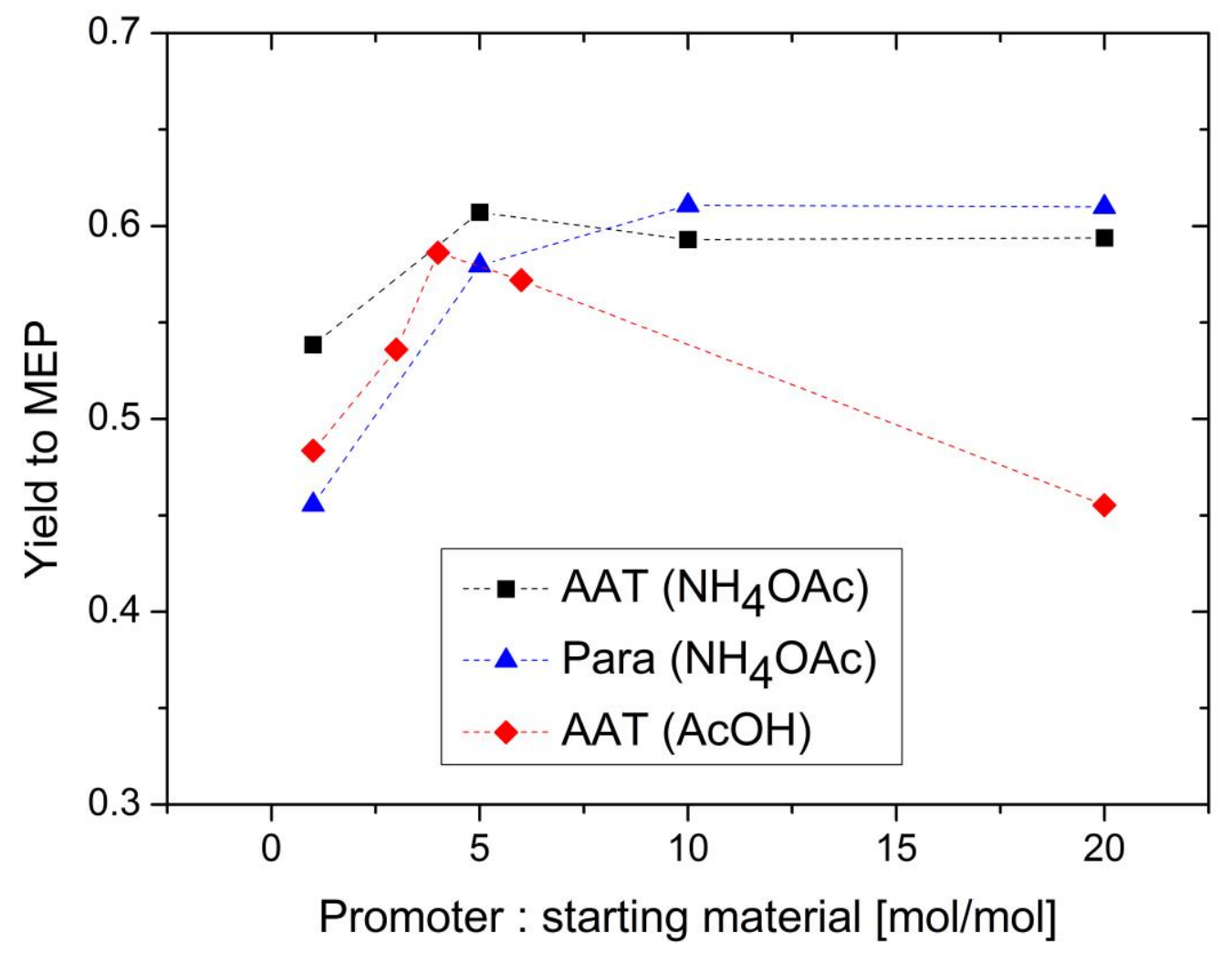

Figure 9 Effect of ratio reactant/promoter on the yield to MEP. Reaction conditions: $T=200{ }^{\circ} \mathrm{C}$, concentration of reactant $5 \%$ wt., feed flow rate $=10 \mathrm{~mL} / \mathrm{min}$

\section{Oligomer characterisation}

In the results described so far, a relevant fraction of the product mixture is composed of oligomeric byproducts. A characterisation of this fraction is necessary to fully understand the course of reaction and to draw the right mechanistic conclusions. LC-MS analysis allows for a qualitative description of the byproduct formation. A representative MS spectrum of the reaction mixture obtained from the reaction of AAT and ammonium acetate is shown in Figure 10. Only molecular weights higher than 121 (MW of MEP) are considered. The distribution of by-products follows a regular scheme, resulting from the consecutive addition of aldimine to the growing oligomer chain followed by the release of ammonia. The structures formed have the general formula $\mathrm{C}_{n} \mathrm{H}_{n+3} \mathrm{~N}$ (MEP would correspond to $n=8$ ). The intensity of the peaks continuously decreases from $\mathrm{MW}=147$ to $\mathrm{MW}=225$. After this latter value, the structure of the products 
changes to the formula $\mathrm{C}_{n} \mathrm{H}_{n+6} \mathrm{~N}_{2}$ meaning that the molecules contain one molecule of ammonia more compared to the previous case.

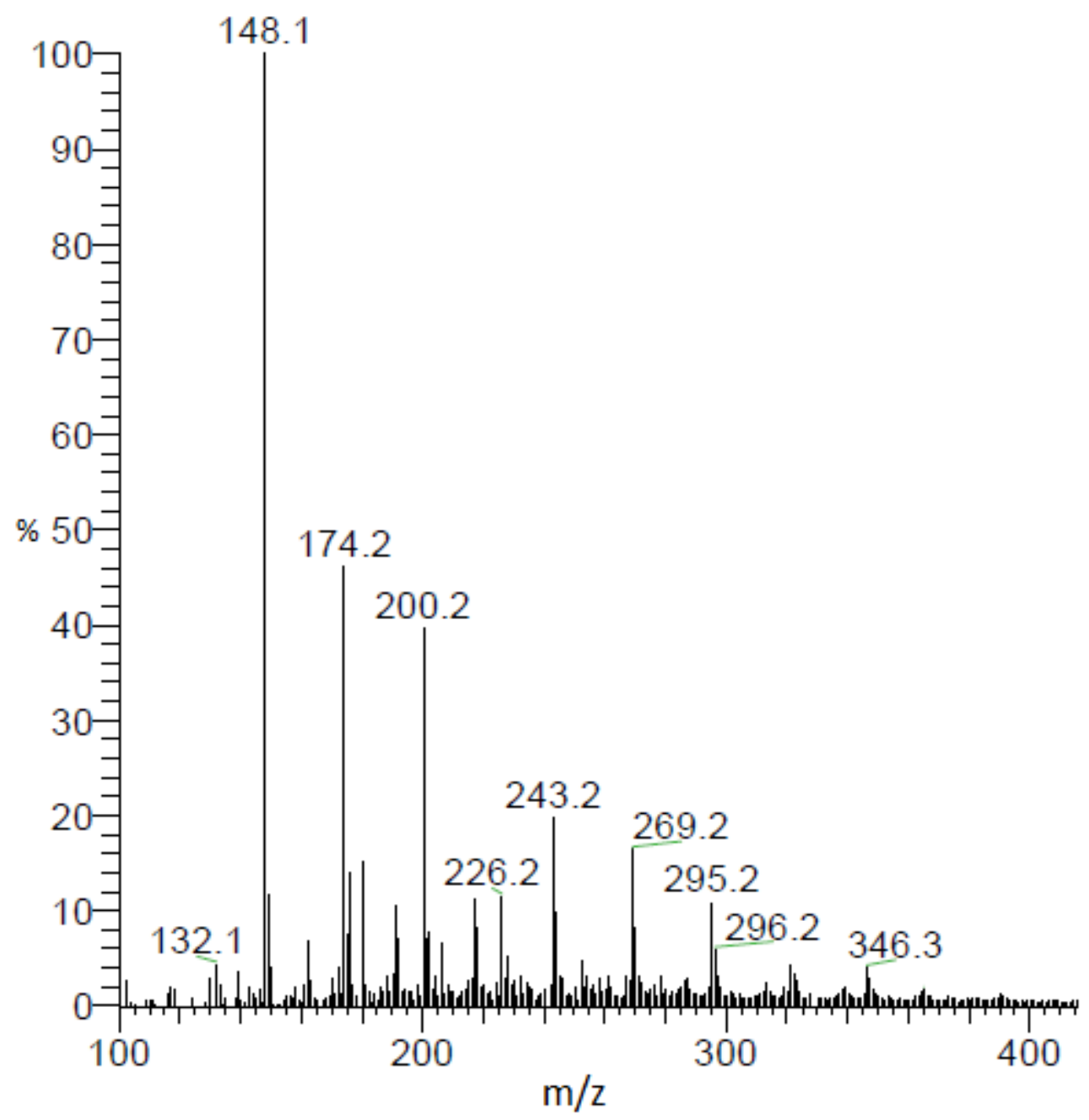

Figure 10 Total ion chromatogram (TIC) in the LC-MS of oligomer by-product during the reaction of AAT and ammonium acetate. Reaction conditions: $T=200{ }^{\circ} \mathrm{C}$, concentration of reactant $5 \% \mathrm{wt}$., ratio AAT/promoter $=1.0 \mathrm{~mol} / \mathrm{mol}$, feed flow rate $=10 \mathrm{~mL} / \mathrm{min}$

The elementary content of $\mathrm{C}, \mathrm{H}$ and $\mathrm{N}$ atoms in the molecules is summarized in Table 4. This analysis is not sufficient to fully characterise the oligomer, but it supports the interpretation that all heavier products result from the same type of chain growth mechanism with the various species being produced by termination of the oligomerisation at different stages. 


\begin{tabular}{|l|l|l|l|}
\hline $\begin{array}{c}\mathrm{m} / \mathrm{z} \text { for } \\
\text { various } \\
\text { products }\end{array}$ & $\mathrm{C}$ & $\mathrm{H}$ & $\mathrm{N}$ \\
\hline 147 & 10 & 13 & 1 \\
\hline 173 & 12 & 15 & 1 \\
\hline 199 & 14 & 17 & 1 \\
\hline 225 & 16 & 19 & 1 \\
\hline 242 & 16 & 22 & 2 \\
\hline 268 & 18 & 24 & 2 \\
\hline 294 & 20 & 26 & 2 \\
\hline 346 & 24 & 30 & 2 \\
\hline
\end{tabular}

Table 4 Results of LC-MS analysis on the oligomer by-products

\section{Mechanistic conclusions}

The proposed simplified reaction scheme for MEP synthesis from AAT and paraldehyde is shown in Figure 11. Both AAT and paraldehyde decompose thermally. AAT forms directly aldimine. Paraldehyde decomposes to acetaldehyde in the presence of an acid catalyst, but decomposes to aldimine if the promoter is an ammonium salt. If the ammonium salt is not present in excess, paraldehyde reacts partially to aldimine and partially to acetaldehyde, which can further react in the aldol condensation. The two decomposition reactions are equilibrium reactions. The intermediate formed can undergo an aldol-type reaction to form longer chain intermediates. The release of ammonia produces unsaturated imines, which can undergo further reactions. When four monomeric species consecutively react, it is possible that an internal condensation to form the pyridine ring takes place. The special configuration of MEP (methyl and ethyl group respectively in 1,4 relative position), together with the simplicity of the reaction (no dehydrogenation required) makes MEP the predominant product of the reaction, with only low production of other pyridine bases. The pathway to 2- and 4-picoline involves a high energy dehydrogenation step, which makes MEP production most favourable. This mechanistic advantage is represented in figure 12. If the ring formation does not take place producing MEP, the chain can further grow to form higher molecular weight species. The internal ring closure is in competition with growing of the chain. This is the crucial step to determine selectivity. The polymeric structures are not well identified; they can be linear, branched or contain several ring entities. The longest chains are formed by the consecutive reaction of 8-10 monomers. Since these oligomers have an average molecular weight higher than MEP, an increase in reactant concentration causes an increase in formation of side products. Higher substrate concentration leads to an increase in intermediate concentration promoting the reaction to oligomer. This reaction proceeds already at low temperature, while formation of pyridine bases requires temperatures higher than $170{ }^{\circ} \mathrm{C}$. The temperature does not influence the reaction mechanism, but only the relative relevance of the two parallel reactions. For this reason, while the ratio oligomer/MEP changes with temperature, no different products are found changing the temperature. 

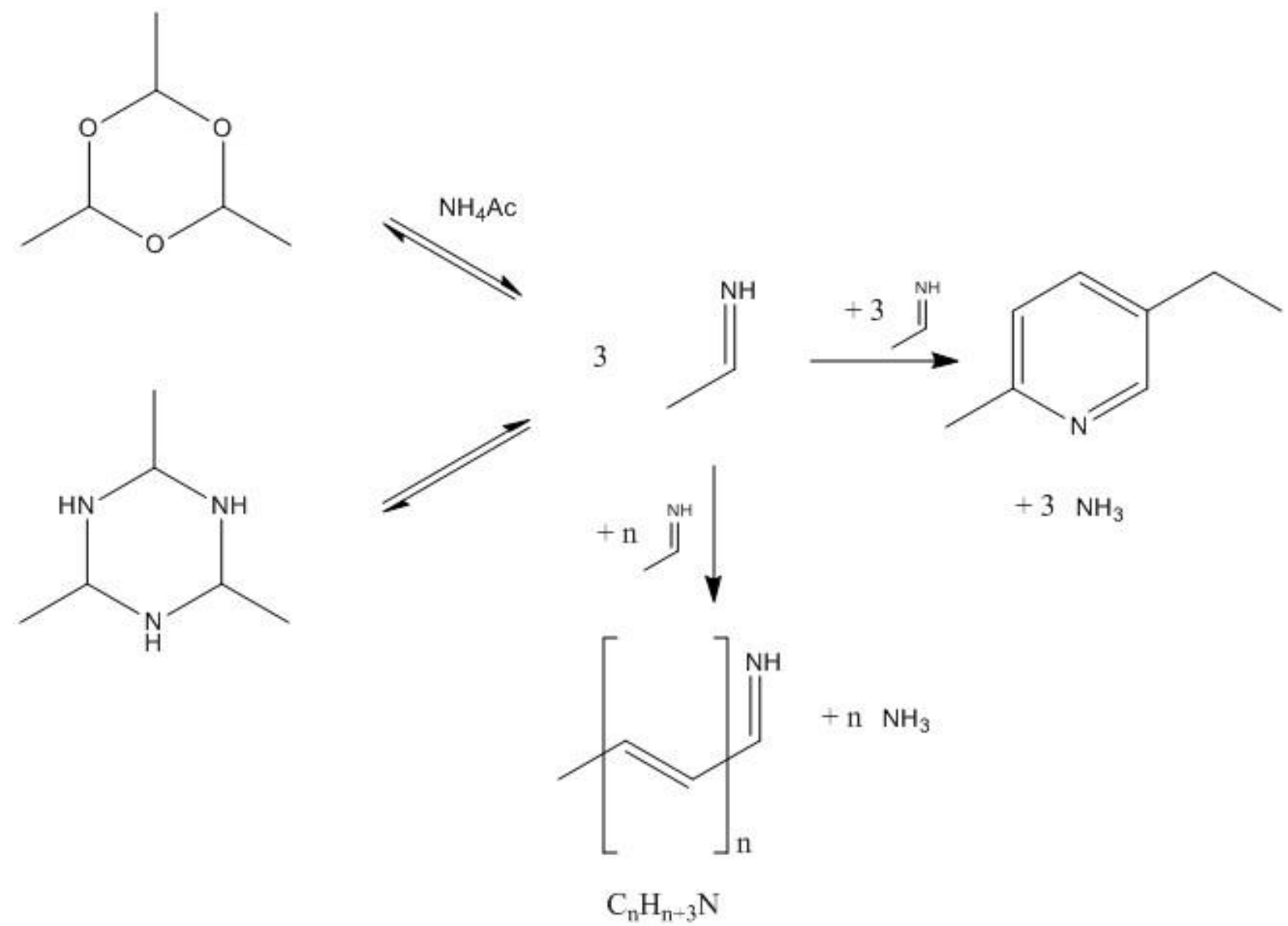

Figure 11 Proposed simplified reaction scheme for the formation on MEP and oligomer from AAT and paraldehyde. 

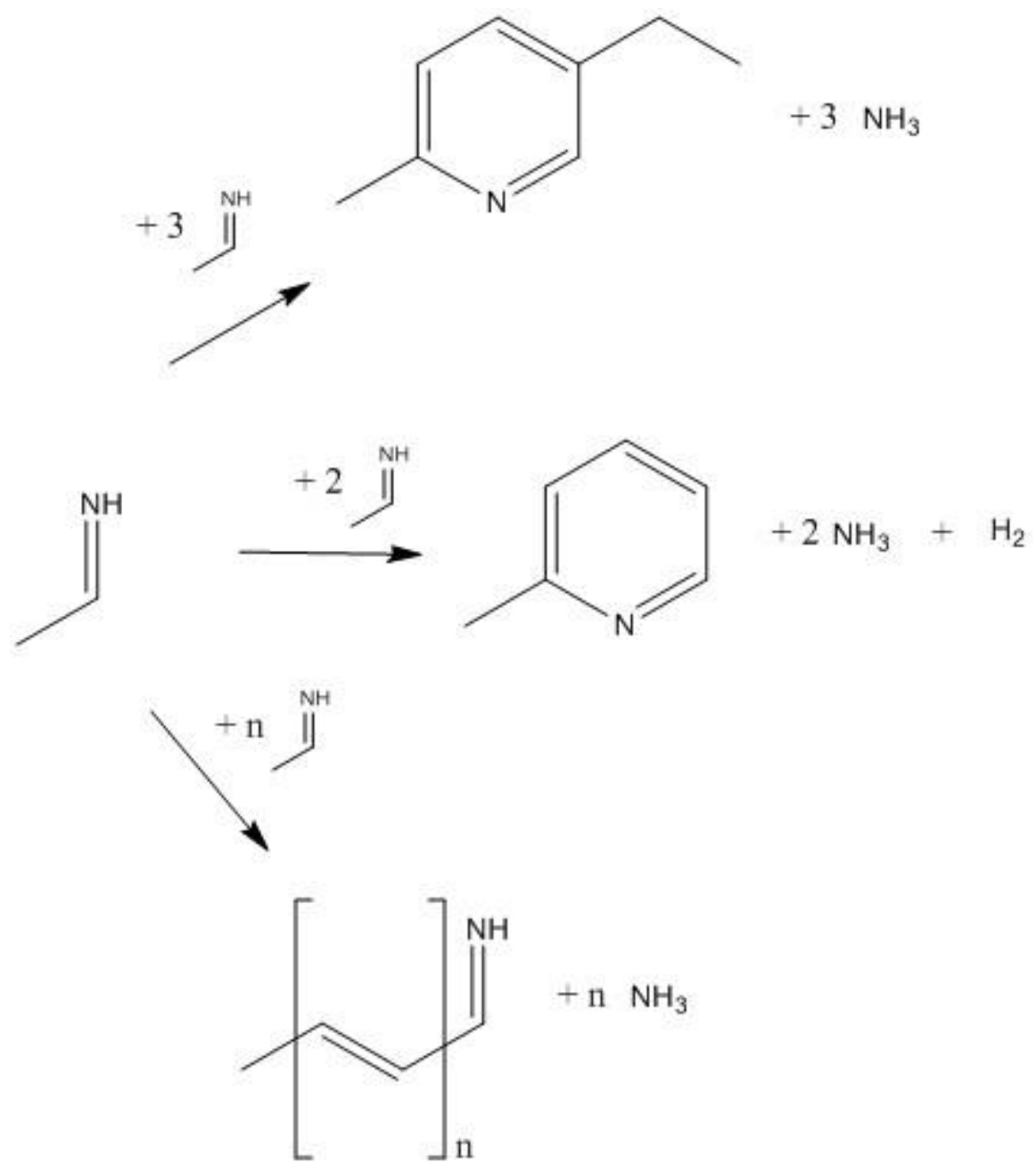

$$
\mathrm{C}_{n} \mathrm{H}_{n-3} \mathrm{~N}
$$

Figure 12 schematic representation of the possible products of the reaction

\section{Conclusion}

A novel reaction route for the synthesis of 2-methyl-5-ethyl-pyridine (MEP) is presented in this study. The route is based on/proceeds via a liquid phase transformation of acetaldehyde ammonia trimer (AAT) in the presence of an acid promoter. The promoter was found to be necessary to obtain MEP in high yield. Ammonium acetate or acetic acid were identified as the most suitable promoters. The most relevant parameters for maximising the MEP yield are temperature and concentration of reactant and promoter. Under the reaction conditions of an isothermal and perfectly mixed reactor, the MEP yield starting from AAT or paraldehyde was found to be comparable. However, the use of AAT allows for carrying out the reaction without addition of ammonia or ammonium acetate. The absence of ammonia allows for applying a significantly lower operating pressure in the production of MEP and makes the downstream processing easier. Moreover, MEP production from AAT is more robust, e. g., the effect of varying ammonia and promoter concentration is relatively limited.

From the obtained results we conclude that both AAT and paraldehyde form aldimine, which is the key intermediate in the reaction to MEP. AAT quantitatively forms the intermediate, while paraldehyde decomposition depends on the quantity and type of the promoter used for the reaction. The reaction of aldimine to MEP is favoured by temperatures between 190 and $210^{\circ} \mathrm{C}$, while increasing substrate concentration favours the competing oligomer formation. 


\section{Acknowledgements}

This project has received funding from the European Union's Seventh Framework Program for research, technological development and demonstration under grant agreement no. 607114.

\section{References}

[1] J.I. Grayson, R. Dinkel, Helv. Chim. Acta, (1984), 67, 2100

[2] R. S. Sagitullin, G. P. Shkil', I. I. Nosonova, A. A. Ferber, Chem. of Het. Comp., (1996), 32, 2

[3] R. Kuhn, G. Wendt, Ber. Dtsch. Chem. Ges. B, (1938) 71, 1118.

[4] P. Karrer, H. Heller, Helv. Chim. Acta, (1939) 22, 1292.

[5] S. Schimizu et al., Pyridine and Pyridine Derivatives, Ullmann's Encyclopedia of Industrial Chemistry, (2012), Wiley-VCH, Weinheim.

[6] A. Hanzsch, Justus Liebigs Ann. Chem., (1882), 215, 72.4

[7] A. E. Chichibabin, Zh. Russ. Fiz. Khim., O-va., (1905), 37, 1229.

[8] A. Nenz, M. Pieroni, Hydrocarbon Process., (1968), 47, 11, 139 - 144.

[9] R. L. Frank, F. J. Pilgrim, E. F. Riener, Org. Synth., (1963), 4, 451.

[10] T. Shoji, N. Abe, Petrotech (Tokyo), (1984), 7, 195

[11] M. I. Farberov. V. V. Antonova, B. F. Ustavshchikov, and N. A. Titova, Khimiya Geterotsiklicheskikh Soedinenii, (1975) 12, 1587-1592

[12] D.C. Frost, B. MacDonald, C. A. McDowell, N. P. C. Westwood, Journal of Electron Spectroscopy and Related Phenomena, (1978), 14 379-390

[13] A. Nielsen, R. Atkins, D. Moore, R. Scott, D. Mallory, J. LaBerge, J. Org. Chem., (1973), 38, 3288-3295

[14] W. Hull, B. Sykes, B. Babior, J. Org. Chem., (1973), 38, 2931-2939.

[15] H. Puchtler, S.N. Meloan, Histochemistry (1981) 72:321-332

[16] V. Vinogradoff, F. Duvernay, M. Farabet, G. Danger, P. Theulé, F. Borget, J.C. Guillemin, T. Chiavassa, J. Phys. Chem. A 2012, 116, 2225-2233

[17] G. Gobron, R. Proust, US Patent 3,594,420, 1971

[18] J. MacLachlan, P. Morken, W. Schmiegel, K. Takahashi, US Patent 6,281,296, 2001

[19] M. Callaway, G.T. Rivers, US Patent 5,958,352, 1999

[20] E. Moioli, L. Schmid, P. Wasserscheid, H. Freund, React. Chem. Eng., (2017) 2, 382-389

[21] C. Rosas, J. Wantuck, A. Kaufman, US Patent 3846435A, 1972 
[22] X. Zhang, C.-W. Luo, C. Huang, B.-H. Chen, D.-G. Huang, J.-G. Pan, Z.-S. Chao, Chem. Eng. J., (2014) 253, 544-553

This work is licensed under the Creative Commons Attribution-NonCommercial 4.0 International License. To view a copy of this license, visit http://creativecommons.org/licenses/by-nc/4.0/ or send a letter to Creative Commons, PO Box 1866, Mountain View, CA 94042, USA. 